\title{
APPLICATION OF HYDROGEN ATMOSPHERE FOR DENSIFICATION OF (Sm,Zr)(Co,Cu,Fe)z MAGNETS
}

\author{
Nikolay A. DORMIDONTOV ${ }^{1}$, Natalia B. KOLCHUGINA ${ }^{1}$, Andrei G. DORMIDONTOV², \\ Gennadiy S. BURKHANOV ${ }^{1}$, Katerina SKOTNICOVA ${ }^{3}$, Pavel A. PROKOFEV ${ }^{1}$, \\ Denis A. RUSINOV 1
}

${ }^{1}$ Baikov Institute of Metallurgy and Materials Science, Russian Academy of Sciences, Moscow, Russian Federation, ontip@mail.ru, natalik014@yandex.ru

2000 MagnitoElektroMekhanika (MEM), Moscow, Russian Federation, doremi.andr@gmail.com

${ }^{3}$ VSB - Technical University of Ostrava, Faculty of Materials Science and Technology, Czech Republic, EU, Katerina.Skotnicova@vsb.cz

https://doi.org/10.37904/metal.2019.955

\begin{abstract}
The effect of hydrogen atmosphere sintering in manufacturing $(\mathrm{Sm}, \mathrm{Zr})(\mathrm{Co}, \mathrm{Cu}, \mathrm{Fe}) z$-based permanent magnets on their properties has been studied. It is shown that sintering in hydrogen, in comparison with sintering in argon, allows obtaining a higher density of billets, while reducing the optimal sintering temperature range by $20^{\circ} \mathrm{C}$. To achieve the same levels of intrinsic coercivity, hydrogen sintered samples require 1.5 times less time of isothermal aging, at the same temperature of heat treatment. In the end, $(\mathrm{Sm}, \mathrm{Zr})(\mathrm{Co}, \mathrm{Cu}, \mathrm{Fe}) z$-based permanent magnets of standard chemical composition sintered in a hydrogen atmosphere, in comparison with sintered in argon, are characterized by higher hysteresis performances: remanence, induction coercivity, intrinsic coercivity and static energy product.
\end{abstract}

Keywords: Rare earth permanent magnets, hydrogen sintering, heat treatment, coercive force

\section{INTRODUCTION}

At present, the importance of permanent magnets based on intermetallic compounds of rare-earth and transition metals for the development of modern technologies in transportation industry, electric drives, renewable energy sources, and electronics cannot be overestimated.

Among the wide range of the aforementioned magnets, sintered $(\mathrm{Sm}, \mathrm{Zr})(\mathrm{Co}, \mathrm{Cu}, \mathrm{Fe}) z$ permanent magnets exhibit the record both thermal stability of hysteretic characteristics and corrosion resistance. These functionally heterophase magnets have the most complex chemical and phase compositions and, therefore, call for the complex treatment technology for reaching the high-coercivity state. Processes of the structure formation, which ensure the efficient domain-wall pinning, until now remain poor understood and are controversial for different research schools. Thus, the main body of studies into the $(\mathrm{Sm}, \mathrm{Zr})(\mathrm{Co}, \mathrm{Cu}, \mathrm{Fe}) \mathrm{z}$ magnets is related to the processes of the phase-structure formation [1-4]. However, there are studies dealing with the improvement of manufacturing processes for these magnets [5-9].

Gaseous hydrogen is traditionally used in manufacturing the rare-earth permanent magnets for decrepitation of alloys and refinement of structure. (1) The traditional, widely used, powder technology of manufacturing the sintered NdFeB magnets includes the hydrogen decrepitation (HD) of alloy, which precedes the fine milling of material to micron-sized powders. (2) In recent years, there are a great number of studies related to the preparation of high-coercivity anisotropic NdFeB-based powders consisting of crystallites $20-40 \mathrm{~nm}$ in size, which are used in manufacturing bonded magnets (magnetoplasts and magnetoelasts). For this purpose, various modifications of the hydrogenation-dispropotionation-decosrbtion-recombination (HDDR) process are realized [10, 11]. In the literature, there are a few works, in which hydrogen was successfully used as the sintering atmosphere for $\mathrm{SmCo}_{5}$ - and $\mathrm{Sm}(\mathrm{Co}, \mathrm{Fe}, \mathrm{Cu})_{7}$-based alloys [12-14]. 
The present study is focused on the investigation of the effect of sintering in a hydrogen atmosphere on the conditions of subsequent manufacturing processes and main parameters of the $(\mathrm{Sm}, \mathrm{Zr})(\mathrm{Co}, \mathrm{Cu}, \mathrm{Fe}) \mathrm{z}$ magnets. In this case, a hydrogen atmosphere is nontraditionally used for sintering, namely, for the consolidation of $(\mathrm{Sm}, \mathrm{Zr})(\mathrm{Co}, \mathrm{Cu}, \mathrm{Fe}) \mathrm{z}$ powders rather than for "opposite" processes, such as decrepitation and disproportionation.

\section{EXPERIMENTAL}

\subsection{Preparation of $(\mathrm{Sm}, \mathrm{Zr})(\mathrm{Co}, \mathrm{Cu}, \mathrm{Fe})_{z}$ magnet samples}

Samples for the investigation, $15 \mathrm{~mm}$ in diameter and $14 \mathrm{~mm}$ in height, were prepared by standard powder metallurgy technology; the easy magnetization axis is along the rotation axis. Two master alloys, the compositions of which correspond to $\mathrm{Sm}_{0.84} \mathrm{Zr}_{0.16}\left(\mathrm{Co}_{0.70} \mathrm{Cu}_{0.07} \mathrm{Fe}_{0.23}\right) z$ with $z=5.6$ and 6.8, were prepared by vacuum induction melting in a high-purity argon atmosphere using starting metals no less than $99.5 \mathrm{wt} \%$ purity. The chemical composition of alloys was controlled by optical atomic-emission spectroscopy with inductively coupled plasma using a Jobin-Yvon Ultima 2 spectrometer. The master alloys were mixed to obtain the $\mathrm{Sm}_{0.84} \mathrm{Zr}_{0.16}\left(\mathrm{Co}_{0.70} \mathrm{Cu}_{0.07} \mathrm{Fe}_{0.23}\right)_{6.25}$ composition and equal volume contents of two main structural components based on SmCo5 and Sm2Co17 phases $[15,16]$. To prevent the powder oxidation, the milling was performed to a powder particles size of $<500 \mu \mathrm{m}$ in a nitrogen atmosphere using a mechanical grinding-mill. Fine powders with an average particle size of 3.5-4 $\mu \mathrm{m}$ were prepared using a vibrating ball mill; mill cylinders were fully filled with absolute isopropyl alcohol used for the oxidation protection. Powder were dried in a vacuum and compacted in an aligned magnetic field of $1.2 \mathrm{MA} / \mathrm{m}$ at a pressure of $80 \mathrm{MPa}$, which was applied perpendicular to the magnetic field direction. The formed blanks were evacuated in elastic envelopes and pressed at a pressure of $250 \mathrm{MPa}$ using a CIP 62330, Avure Technologies installation intended for cold isostatic pressing. The pressed blanks were progressively subjected to four heat treatments (in resistance furnaces), which include the sintering $\left(T_{\text {SINT }}=1180-1220{ }^{\circ} \mathrm{C}\right)$, heat treatment for high-temperature solid solution homogenizing, $\left(T_{S S H T}=1160-1175{ }^{\circ} \mathrm{C}\right)$, quenching, and two sequential annealings, namely, isothermal annealing $\left(T_{I A}=800^{\circ} \mathrm{C}\right)$ and slow-cooling (stepped) annealing $\left(T_{S A}=800-400{ }^{\circ} \mathrm{C}\right)$.

Taking into account preliminarily obtained results, the blanks were sintered using two regimes, namely, (i) in argon and (ii) in hydrogen atmosphere. (i) In the course of sintering in an argon atmosphere, the degassing was performed during heating to certain temperatures at a rate of $200 \% \mathrm{~h}$ in a vacuum of no worse than $1 \times 10^{-}$ ${ }^{2} \mathrm{~Pa}$. After degassing, argon was fed (with a controlled flow rate) into a furnace chamber and samples were heated to the sintering temperature. (ii) During sintering in a hydrogen atmosphere, the degassing was performed without changing atmosphere, i.e., in the hydrogen atmosphere; the samples were heated at the same rate to the same temperatures in a hydrogen flow. The heating rate after degassing to the sintering temperature in argon and hydrogen atmospheres was $1000 \%$; the holding at the sintering temperature is $1 \mathrm{~h}$.

\subsection{Optimization of the degassing of powder blanks before sintering}

To reveal the effect of degassing of the $\mathrm{Sm}_{0,84} \mathrm{Zr}_{0,16}\left(\mathrm{Co}_{0,70} \mathrm{Cu}_{0,07} \mathrm{Fe}_{0,23}\right)_{6,25}$ mixture, "model" samples with a fortiori high gas-impurity contents were were prepared. The fine dry alloy-mixture powder (layer $6 \mathrm{~mm}$ thick) was uniformly applied on a metallic pool and held in air at room temperature for $24 \mathrm{~h}$. After that, the powder was compacted in accordance to standard conditions to form compact aligned blanks, which was subsequently subjected to cold isostatic pressing (CIP). Mechanically compacted powder samples were subjected to degassing parallel in (i) a vacuum of no more than $1 \times 10^{-2} \mathrm{~Pa}$ and (ii) a hydrogen flow. In both cases, the samples were heated at a rate of $200 \% \mathrm{~h}$, held for $1 \mathrm{~h}$ at a fixed temperature, 200, 400,600, 800, and 1000 ${ }^{\circ} \mathrm{C}$, and subjected to furnace cooling in the same atmosphere. After degassing in the vacuum and final cooling of samples, before discharge of samples, the furnace was filled with nitrogen to normal atmospheric pressure. 
The analogous gas change was performed for the furnace with the hydrogen atmosphere (traditional procedure). The samples discharged from the furnace, were placed in plastic bags and evacuated. "Model" samples were used to determine the hydrogen and oxygen contents in them using standard procedures and LECO RHEN-602 and TC-600 analyzers, respectively.

\subsection{Other methods of investigation}

To determine the melting temperatures of individual phase components, the master alloys were studied by differential thermal analysis (DTA) using a DSC 404 F3 Pegasus (NETZSCH GmbH) combined installation. The magnetization curves of sintered samples were measured in fields to $\pm 2 \mathrm{MA} / \mathrm{m}$ using a $L D J-5500 \mathrm{H}$ hysteresisgraph; the coercive force values $H_{C J}$ were determined using small cut samples and a PPMS-9T "Quantum Design" installation. The samples were cut by hydro-abrasive cutting and subjected to diamond grinding. The density of samples was determined by hydrostatic weighing.

\section{RESULTS}

\subsection{Melting temperatures of low-melting phases in the $(\mathrm{Sm}, \mathrm{Zr})(\mathrm{Co}, \mathrm{Cu}, \mathrm{Fe}) z$ alloys}

Figure 1 shows DTA curves for the $\mathrm{Sm}_{0.84} \mathrm{Zr}_{0.16}\left(\mathrm{Co}_{0.70} \mathrm{Cu}_{0.07} \mathrm{Fe}_{0.23}\right) z$ master alloys with $\mathrm{z}=5.6$ and 6.8. Thermal effects observed in the DTA curves allow us to assume that these alloys have qualitatively similar phase compositions. The alloys are likely to differ in the ratio of phase components. In this paper we do not discuss in detail solid-phase transformations in alloys. As for the solid-liquid and liquid-solid phase transformations of individual phases, they occur at temperatures $1190-1192{ }^{\circ} \mathrm{C}, 1205-1210{ }^{\circ} \mathrm{C}$; the other transformations take place above $1220^{\circ} \mathrm{C}$ and correspond to the available knowledge about the phase formation in the fivecomponent Sm-Zr-Co-Cu-Fe system [17, 18]. The obvious compositions of the low-melting phases are $\mathrm{Sm}_{\times}\left(\mathrm{Co}_{0.5} \mathrm{Cu}_{0.4} \mathrm{Fe}_{0.1}\right) z$ with more probable x-to-z ratios of 1:5, 5:19, and 2:7 [15].

\subsection{Refining of $(\mathrm{Sm}, \mathrm{Zr})(\mathrm{Co}, \mathrm{Cu}, \mathrm{Fe})_{z}$ alloys upon degassing during sintering}

Since, according to data given in Figure 1, the both alloys have the qualitatively identical phase compositions, the other experiments were performed using the mixture of master alloys, which allows us, in using standard technology, to reach high hysteretic parameters, in particular, the maximum squareness of hysteresis loops.

Figure 2 shows data on the impurity composition of the "model" mixture, which was subjected to degassing under conditions used for the powder $\mathrm{Sm}_{0.84} \mathrm{Zr}_{0.16}\left(\mathrm{Co}_{0.70} \mathrm{Cu}_{0.07} \mathrm{Fe}_{0.23}\right)_{6.25}$ blanks. In accordance with available knowledge, during vacuum degassing of blanks, the oxygen content decreases during heating in a temperature range of 20 to $200-300{ }^{\circ} \mathrm{C}$. For the considered "model" mixture, the oxygen content decreases from [O] $=0.6$ wt $\%$ to $[O]=0.34-0.37 \mathrm{wt} \%$. During degassing at high temperatures of $400,600,800$, and $1000{ }^{\circ} \mathrm{C}$, the oxygen content is unchanged. The hydrogen content in these samples is unchanged $-[H]=0.0015-0.0020 \mathrm{wt} \%$.

Another dynamics is observed during degassing in a hydrogen atmosphere. During heating in a hydrogen atmosphere, the oxygen content in "model" samples decreases from $[\mathrm{O}]=0.6 \mathrm{wt} \%$ at room temperature to $[\mathrm{O}]=0.17 \mathrm{wt} \%$ at a temperature of the end of degassing of $600^{\circ} \mathrm{C}$ and remains equal to $[\mathrm{O}]=0.16-0.17 \mathrm{wt} \%$ as the temperature increases to $1000^{\circ} \mathrm{C}$. Hydrogen demonstrates another behavior. As the temperature of the end of degassing increases, the hydrogen content monotonically increases from $[\mathrm{H}]=0.0018 \mathrm{wt} \%$ at room temperature to $[\mathrm{H}]=0.0083 \mathrm{wt} \%$ at $1000^{\circ} \mathrm{C}$. In this case, above $600{ }^{\circ} \mathrm{C}$, the increase in the hydrogen content in "model" samples becomes almost linear.

\subsection{Effect of sintering atmosphere for $(\mathrm{Sm}, \mathrm{Zr})(\mathrm{Co}, \mathrm{Cu}, \mathrm{Fe})_{\mathrm{z}}$ magnets}

All subsequent experimental results were obtained for the material, which was not preliminary saturated with gas-forming impurities and the maximum protection, with respect of oxygen, of powders and powder compacts 
was realized between process operations. Figure 3 shows results of measurements of the hydrostatic density of samples sintered in argon and hydrogen atmospheres with different temperatures of the end of degassing.
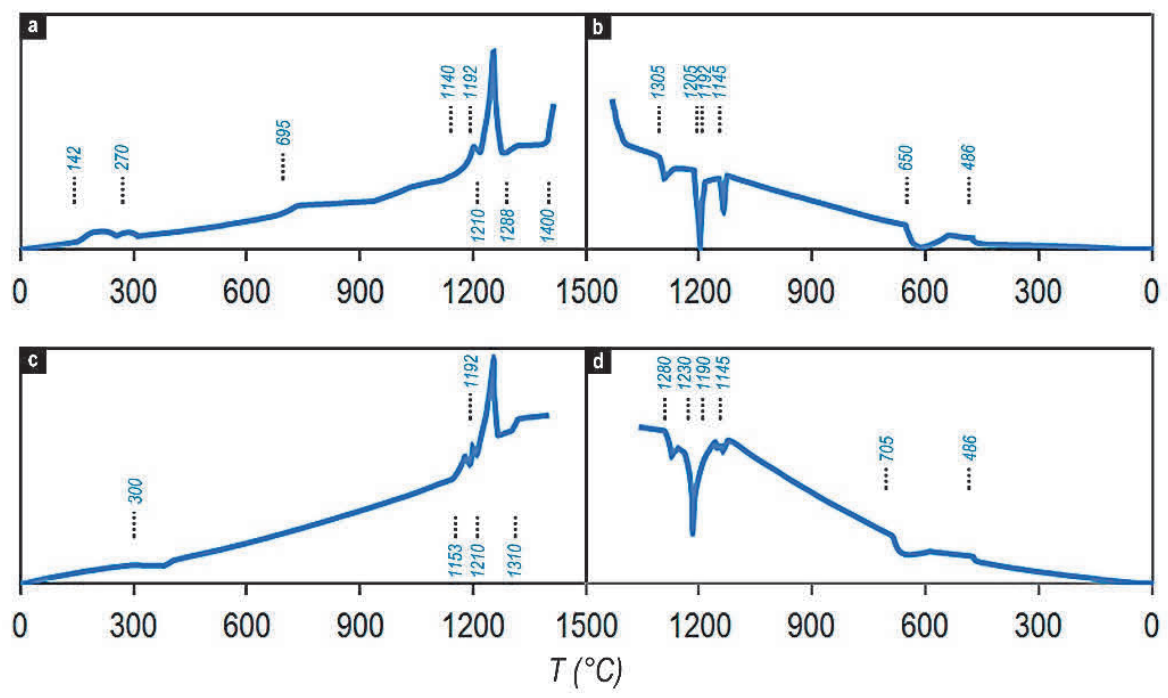

Figure 1 DTA curves measured during heating (left) and cooling (right) of the $\mathrm{Sm}_{0.84} \mathrm{Zr}_{0.16}\left(\mathrm{Co}_{0.70} \mathrm{Cu}_{0.07} \mathrm{Fe}_{0.23}\right) \mathrm{z}$ alloys with $z=5.6$ (top) and $z=6.8$ (bottom) at a rate of $30^{\circ} \mathrm{C} / \mathrm{min}$. Digits near thermal effects corresponds to the temperatures $\left({ }^{\circ} \mathrm{C}\right)$ of the onset of phase transformations.

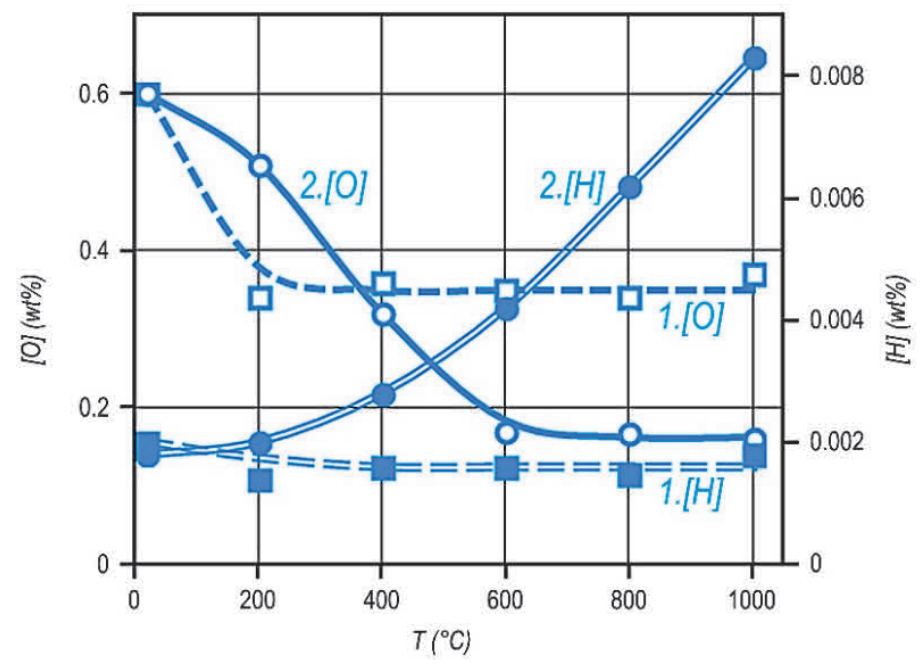

Figure 2 Hydrogen $[\mathrm{H}]$ and oxygen $[\mathrm{O}]$ contents in samples of "model" Sm0.84Z $\mathrm{Zr}_{0.16}\left(\mathrm{Co}_{0.70} \mathrm{Cu}_{0.07} \mathrm{Fe}_{0.23}\right)_{6.25}$ mixture after degassing upon heating to temperatures of $200,400,600,800,100{ }^{\circ} \mathrm{C}$ in (1) vacuum and (2) hydrogen

It is obvious that the dependences exhibit qualitatively different behaviors. During sintering in an argon atmosphere, the density of samples monotonically increases as the degassing temperature increases from room temperature to $400{ }^{\circ} \mathrm{C}$; subsequently, the density of samples almost is unchanged and reaches $\rho=8.16$ $8.18 \mathrm{~g} / \mathrm{cm}^{3}$. The dependence of the hydrostatic density of samples on the degassing temperature during sintering in a hydrogen atmosphere is nonmonotonic and has an extremum, maximum, corresponding to $\rho=$ 8.30-8.32 $\mathrm{g} / \mathrm{cm}^{3}$. The both dependences, corresponding to sintering in argon and hydrogen, exhibit the increase in the density in accordance with the decrease in the oxygen content in "model" samples (see Figure 2). As the oxygen content stabilizes, the increase in the density stops. 


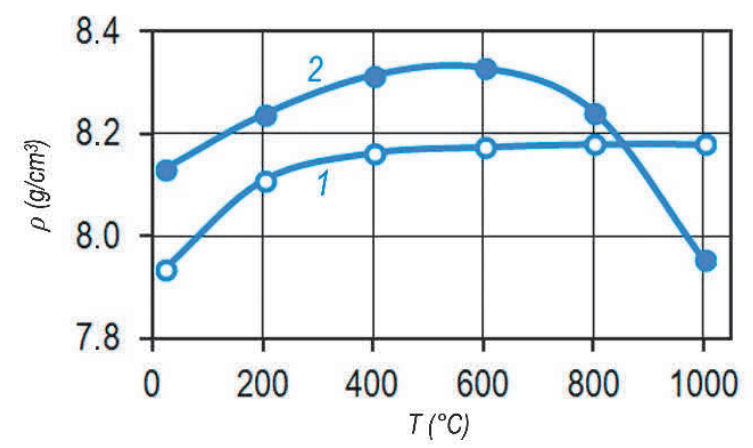

Figure 3 Hydrostatic density of samples prepared from the "pure" $\mathrm{Sm}_{0,84} \mathrm{Zr}_{0,16}\left(\mathrm{Co}_{0,70} \mathrm{Cu}_{0,07} \mathrm{Fe}_{0,23}\right)_{6,25}$ powder and sintered in argon $\left(\mathrm{T}_{\text {sint. }}=1215^{\circ} \mathrm{C}\right.$, curve

1 ) and hydrogen $\left(T_{\text {sint. }}=1195^{\circ} \mathrm{C}\right.$, curve 2$)$ atmospheres with preliminary degassing by regimes used for "model" samples (see Figure 2)
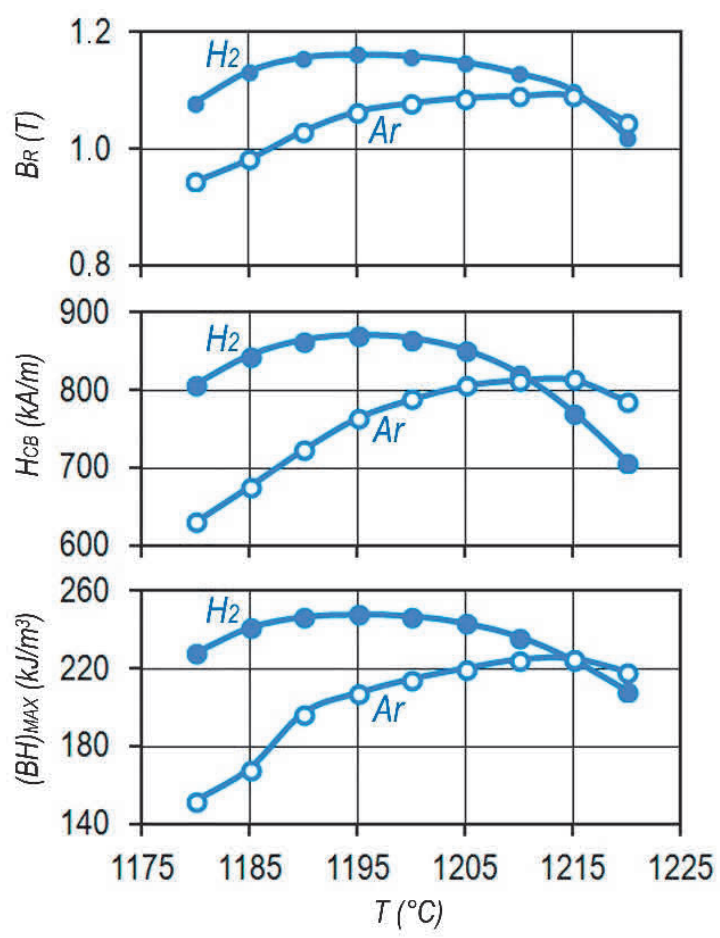

Figure 5 Principal magnetic parameters (residual magnetization $4 \pi J_{R}$, induction coercive force $H_{C B}$, and maximum energy product $(B H)_{\max }$ ) of the $\mathrm{Sm}_{0.84} \mathrm{Zr}_{0.16}\left(\mathrm{Co}_{0.70} \mathrm{Cu}_{0.07} \mathrm{Fe}_{0.23}\right)_{6.25}$ magnets as functions of the temperature of sintering in argon ( $\mathrm{Ar}$ ) and hydrogen $\left(\mathrm{H}_{2}\right)$ atmospheres
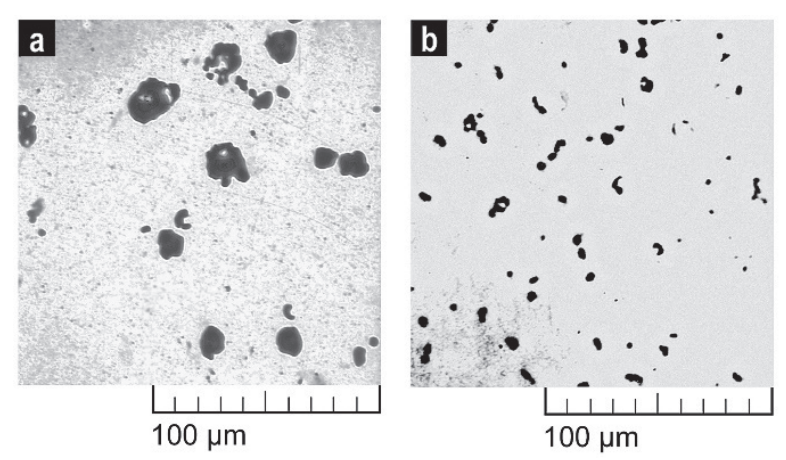

Figure 4 Morphology of porosity of $\mathrm{Sm}_{0.84} \mathrm{Zr}_{0.16}\left(\mathrm{Co}_{0.70} \mathrm{Cu}_{0.07} \mathrm{Fe}_{0.23}\right)_{6.25}$ magnet samples sintered in accordance with optimum conditions in argon at $T_{\text {sint. }}=1215^{\circ} \mathrm{C}$ (a) and hydrogen at $T_{\text {sint. }}$ $=1195^{\circ} \mathrm{C}(\mathrm{b})$

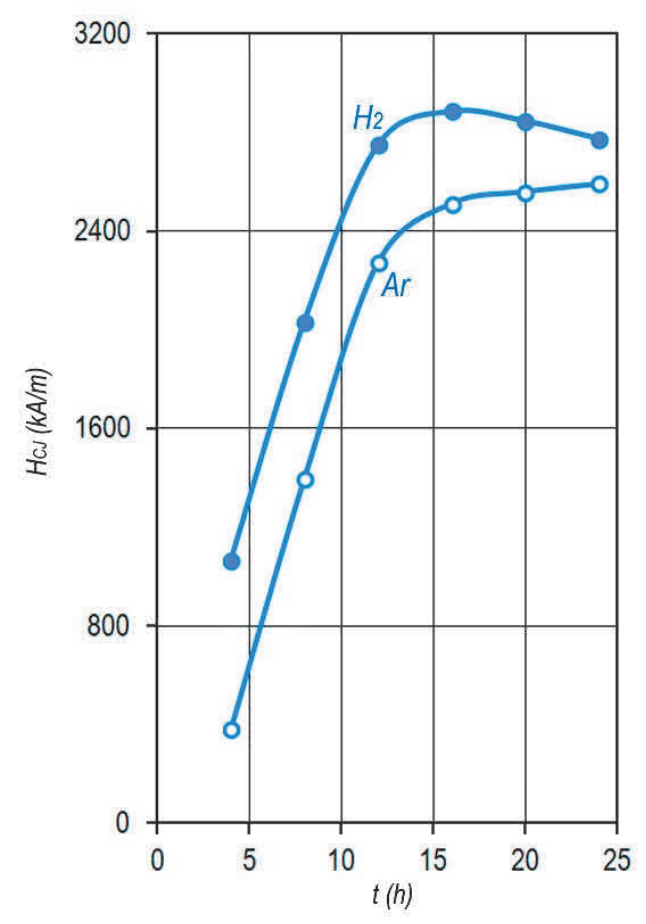

Figure 6 Dependence of the intrinsic coercive force $\left(\mathrm{H}_{\mathrm{CJ}}\right)$ of the $\mathrm{Sm}_{0,84} \mathrm{Zr}_{0,16}\left(\mathrm{Co}_{0,70} \mathrm{Cu}_{0,07} \mathrm{Fe}_{0,23}\right)_{6,25}$ magnets sintered in argon $(\mathrm{Ar})$ and hydrogen $\left(\mathrm{H}_{2}\right)$ atmospheres on the time of isothermal aging; measurements were performed after stepped annealing

Figure 4 shows the morphology and the porosity of $\mathrm{Sm}_{0.84} \mathrm{Zr}_{0.16}\left(\mathrm{Co}_{0.70} \mathrm{Cu}_{0.07} \mathrm{Fe}_{0.23}\right)_{6.25}$ samples sintered in accordance with the optimum conditions in an argon atmosphere with degassing to $250^{\circ} \mathrm{C}$ and $T_{\text {sint. }}=1215^{\circ} \mathrm{C}$ and in a hydrogen atmosphere with the temperature of the end of degassing of $600^{\circ} \mathrm{C}$ and $T_{\text {спек. }}=1195^{\circ} \mathrm{C}$. The structure of sample sintered in hydrogen is characterized by uniformly distributed mainly submicron-sized pores and is considered to be preferable. 
Figure 5 shows dependences of the principal magnetic characteristics of the $(\mathrm{Sm}, \mathrm{Zr})(\mathrm{Co}, \mathrm{Cu}, \mathrm{Fe}) z$ magnets sintered in argon and hydrogen atmospheres (optimum degassing conditions were used) on the sintering temperature. It is obvious that the optimum temperature range of sintering in a hydrogen atmosphere decreases from $1210-1220$ to $1190-1200{ }^{\circ} \mathrm{C}$ and is accompanied by the simultaneous increase in the density of blanks.

\subsection{Dynamics of formation of high-coercivity state of $\mathrm{Sm}_{0.84} \mathrm{Zr}_{0.16}\left(\mathrm{Co}_{0.70} \mathrm{Cu}_{0.07} \mathrm{Fe}_{0.23}\right)_{6.25}$ magnets sintered in argon and hydrogen}

Figure 6 shows the increase in the coercive force of $\mathrm{Sm}_{0,84} \mathrm{Zr}_{0,16}\left(\mathrm{Co}_{0,70} \mathrm{Cu}_{0,07} \mathrm{Fe}_{0,23}\right)_{6,25}$ magnets sintered in argon and hydrogen atmospheres in accordance with optimum conditions, which is plotted as a function of the time of isothermal aging. After sintering, all samples were subjected to heat treatment for the high-temperature solid solution, and, after isothermal aging, were subjected to stepped annealing. The samples sintered in a hydrogen atmosphere exhibit the higher rate of increase in the coercive force; the high values are reached both at each moment of time and finally. It is seen that, to reach the equal values of coercive force after sintering in argon, the time is one and a half times higher than that taken for the sintering in hydrogen.

\section{DISCUSSION}

In accordance with formula $4 \pi J=4 \pi \sigma \rho$ (where $J$ is magnetization; $\sigma$ is unit magnetization; and $\rho$ is the density), the density of magnet substantially determines the final hysteretic parameters, i.e., the maximum densification of powder material during sintering is one of important manufacturing tasks. Other things being equal, it is reached when (i) the maximum purity of initial powder blank is reached and increases before the sintering and (ii) the sufficient amount of liquid phase is reached, which ensures the increase in mass transfer between crystallites at the expense of etching the particle surface and the efficient assistance in consolidation of particles at the expense of surface tension.

The recrystallization processes in the alloy, which occur during sintering, should be limited in a certain temperature range. The too intense grain growth in the alloy during sintering can lead a decrease in the squareness of hysteresis loop, degradation of residual magnetization and maximum energy product of samples. The third condition for the densification of magnets is (iii) sintering at minimally possible temperature.

The comparison of data given in Figures 2, $\mathbf{3}$ and $\mathbf{4}$ show clearly that the use of refining ability of hydrogen allows us to reach the higher density of samples at the lower sintering temperature, other thing being equal.

During sintering in a hydrogen atmosphere, the slow heating to temperature above $600{ }^{\circ} \mathrm{C}$ leads the decrease in the density; this is likely to be related to the onset of intense hydrogen absorption (see Figure 2, curve 2 $[\mathrm{H}])$. The high hydride absorption can (i) lead to "swelling up" a blank during slow heating in the case of formation of complex hydrides of intermetallic phases $\mathrm{Sm}_{x}(\mathrm{TM})_{y} \mathrm{H}_{\delta}$ and (ii) to take samarium from Sm-rich intermetallics 1:5, 5:19 and 2:7 and, thus, to decrease the amount of these phases in the alloy and to form the samarium hydride. Both these facts should lead to the decrease in the final density of sintered samples. In the case of "swelling" of a sample, the efficiency of liquid phase formed at the sintering temperature decreases. In the case of formation of samarium hydride, the amount of low-melting phases, which ensure the liquid-phase sintering, decreases; this must negatively effect the density of sintered blanks. The results obtained for the "model" material (Figure 2) clearly show that the high reducing ability of hydrogen atmosphere is the most efficient for refining the powders directly before sintering to temperature below $600{ }^{\circ} \mathrm{C}$. It should be noted that, after sintering in a hydrogen atmosphere, in contrast to the sintering in an argon atmosphere, the density of samples increases during solid-solution heat treatment (homogenization) more increases by $0.03-0.05 \mathrm{~g} / \mathrm{cm}^{3}$ [19].

In accordance with available literature data and data given in Figure 1, it is obvious that the sintering of $(\mathrm{Sm}, \mathrm{Zr})(\mathrm{Co}, \mathrm{Cu}, \mathrm{Fe})_{\mathrm{z}}$ alloys occurs via the liquid-phase mechanism without the special introduction of a low- 
melting addition to the starting composition. This means that starting alloy in the as-cast state contains a phase (or phases) with the melting temperature below the sintering of blanks. According to the data given in Figure 5, the optimum temperatures of traditional sintering (in argon) of samples are $1210-1220^{\circ} \mathrm{C}$. Thus, for efficient realization densification process during sintering in an inert gas atmosphere, the liquid phase consisting of at least two phase components (their volume contents) should be formed, which transfer to liquid state in temperature range of $1190-1192$ and $1205-1210^{\circ} \mathrm{C}$ (see Figure 1). It is likely that the amount of melt formed as a result of solid-liquid transition of low-melting phase $\left(T_{m} \sim 1190{ }^{\circ} \mathrm{C}\right)$ is insufficient to ensure the efficient realization of sintering in an argon atmosphere. On the contrary, during sintering in a hydrogen atmosphere, the optimum sintering temperatures are in a range of $1190-1200^{\circ} \mathrm{C}$ and correspond to the melting temperature range of low-melting component of material. Along with the intense preliminary refining of samples, this results in the increase in the density and principal hysteretic parameters of samples.

The reached higher density of material during sintering in a hydrogen atmosphere in itself must give the effect of the increase in the principal characteristics of magnets, whereas the more efficient consolidation of particles during sintering, along with the simultaneous decrease in the amount of liquid phase, should lead to the increase in the effect during subsequent heat treatments. This is demonstrated by data on the dependence of the coercive force on the time of isothermal annealing (Figure 6). It should be noted that, in the present study, we used the $\mathrm{Sm}_{0.84} \mathrm{Zr}_{0.16}\left(\mathrm{Co}_{0.70} \mathrm{Cu}_{0.07} \mathrm{Fe}_{0.23}\right)_{6.25}$ alloy, in which the proportion of elements is optimum for the technology assuming the sintering in an argon atmosphere. It is likely that, in using sintering in a hydrogen atmosphere, in order to obtain magnets with ultimate hysteretic characteristics, the chemical composition of the alloy should be optimized taking into account all advantages of the reducing atmosphere.

\section{CONCLUSIONS}

The sintering of $(\mathrm{Sm}, \mathrm{Zr})(\mathrm{Co}, \mathrm{Cu}, \mathrm{Fe}) z$ magnets in a hydrogen atmosphere is shown to have a number of advantages over the traditional sintering process in an argon atmosphere. During optimum sintering of $(\mathrm{Sm}, \mathrm{Zr})(\mathrm{Co}, \mathrm{Cu}, \mathrm{Fe})_{z}$ magnets in a hydrogen atmosphere, (1) the more substantial refinement of samples takes place; (2) the reached density of samples is higher; (3) the optimum temperature range of sintering in a hydrogen atmosphere is $20^{\circ} \mathrm{C}$ lower than that of sintering in an argon atmosphere; (4) the rate of formation of high-coercivity state upon isothermal annealing increases; this results in the decrease in the aging time by 1.5 times; (5) the higher principal hysteretic parameters of $(\mathrm{Sm}, \mathrm{Zr})(\mathrm{Co}, \mathrm{Cu}, \mathrm{Fe})_{z}$ magnets sintered in a hydrogen atmosphere, as compared to those of magnets prepared by traditional technology, are reached.

\section{ACKNOWLEDGEMENTS}

The study was supported by Russian Foundation for Basic Research, project no. 18-33-01070-mol_a.

\section{REFERENCES}

[1] DUERRSCHNABEL, M., YI, M., UestueneR, K., LIESEGANG, M., KATTER, M., KLEEBE, H-J., Xu, B., GUTFLEISCH, O. and MOLINA-LUNA, L. Atomic structure and domain wall pinning in samarium-cobalt-based permanent magnets. Nature Communications. 2017. vol. 8, no. 1, 54.

[2] SONG, K., SUN, W., CHEN, H., YU, N., FANG, Y., ZHU, M. and LI, W. Revealing on metallurgical behavior of iron-rich $\mathrm{Sm}(\mathrm{Co} 0.65 \mathrm{Fe} 0.26 \mathrm{Cu0} 07 \mathrm{Zr0.02}) 7.8$ sintered magnets. AIP Advances. 2017. vol. 7, 056238.

[3] SONG, K., FANG, Y., WANG, SH., YU, N., CHEN, H., ZHANG, M., ZHU, M. and LI, W. Crystalline and magnetic microstructures of iron-rich $\mathrm{Sm}(\mathrm{Co} 0.65 \mathrm{Fe} 0.26 \mathrm{Cu} 0.07 \mathrm{Zr0.02}) 7.8$ sintered magnets: Isothermal aging effect. Journal of Magnetism and Magnetic Materials. 2018. vol. 465, pp. 569-577.

[4] ZHANG, Ch., LIU, Z., LI, M. LIU, L., LI, T., CHEN, R., LEE, D. and YAN, A. The evolution of phase constitution and microstructure in iron-rich 2:17-type Sm-Co magnets with high magnetic performance. Scientific Reports. 2018. 8:9103. 
[5] ZHANG, W., ZHAO, R., FANG, Y., ZHOU, M., ZHU, M. and LI, W. Effect of Sm-rich liquid phase on magnetic properties and microstructures of sintered 2:17-type Sm-Co magnet. Journal of Rare Earths. 2011. vol. 29, no. 10, pp. 934-938.

[6] LIU, L., LIU, Z., CHEN, R., LIU, X., YAN, A., LEE, D. and LI, W. Effect of strip casting on microstructure and magnetic properties of 2:17 Type Sm-Co sintered magnets. IEEE Transactions on Magnetics. 2014. vol. 50, no. 1, 2101704.

[7] HORIUCHI, Y., HAGIWARA, M., OKAMOTO, K., KOBAYASHI, T., ENDO, M., KOBAYASHI, T., NAKAMURA and SAKURADA, Sh. Effects of solution treated temperature on the structural and magnetic properties of iron-rich sintered magnet. IEEE Transactions on Magnetics. 2013. vol. 49, no. 7, pp. 3221-3224.

[8] HORIUCHI, Y., HAGIWARA, M., OKAMOTO, K., KOBAYASHI, T.S., ENDO, M., KOBAYASHI, T., SANADA, N. and SAKURADA, Sh. Effect of pre-aging treatment on the microstructure and magnetic properties of $\mathrm{Sm}(\mathrm{Co}, \mathrm{Fe}, \mathrm{Cu}, \mathrm{Zr}$ )7.8 sintered magnets. Materials Transactions. 2014. vol. 55, no. 3, pp. 482-488.

[9] HORIUCHI, Y., HAGIWARA, M., ENDO, M., SANADA, N. and SAKURADA, Sh. Influence of intermediate-heat treatment on the structure and magnetic properties of iron-rich $\mathrm{Sm}(\mathrm{CoFeCuZr}) \mathrm{Z}$ sintered magnets. Journal of Applied Physics. 2015. vol. 117, 17C704.

[10] GUTFLEISCH, O., KHLOPKOV, K., TERESIAK, A., MÜLLER, K-H., DRAZIC, G., MISHIMA, C. and HONKURA, Y. Memory of texture during HDDR processing of NdFeB. IEEE Trans. on Magn. 2003. vol. 39, no. 5, pp. 29262931.

[11] HONKURA, Y., MISHIMA, C., HAMADA, N., DRAZIC, G. and GUTFLEISCH, O. Texture memory effect of Nd-FeB during hydrogen treatment. Journal of Magnetism and Magnetic Materials. 2005. vol. 290-291, pp. 1282-1285.

[12] JONES, F. G., DOSER, M. and NEZU, T. Hydrogen Atmosphere Sintering of Cobalt-Samarium Magnets. IEEE Transactions on Magnetics. 1977. vol. MAG-13, no. 5, pp. 1320-1322.

[13] Patent 3970 484, U.S. DOSER, M and JONES, F. G. 20.07.1976

[14] ISHIGAKI, N. and MAJIMA, K. Effects of sintering atmosphere on the magnetic properties of $\mathrm{Sm}(\mathrm{Co}, \mathrm{Fe}, \mathrm{Cu}) 7$ permanent magnet alloy. Journal of the Japan Society of Powder and Powder Metallurgy. 1983. vol. 30, no. 1, pp. 12-20.

[15] DORMIDONTOV, A.G., SUPONEV, N.P., LEVANDOVSKY, V.V., SHAMORIKOVA, E.B. and NEKRASOVA, E.M. High coercivity alloys of $(\mathrm{Sm}, \mathrm{Zr})(\mathrm{Co}, \mathrm{Cu}, \mathrm{Fe}) \mathrm{z}$ for permanents magnets. Electronics industry (Russia). 1991. no. 12, pp.18-23.

[16] SEMENOVA, E. M., LYAKHOVA, M. B., IVANOVA, A. I. and ULYANOV, M. N. Micro- and nanostructures of RCoCuFeZr heterogeneous alloys with high temperature stability. Materials Science Forum. 2016. vol. 845, pp. 46-49.

[17] KIANVASH, A. and HARRIS, I. R. metallographic studies of A 2-17-Type Sm(Co,Cu,Fe,Zr)8.92 magnetic alloy. Journal of the Less-Common Metals. 1984, vol. 98, pp. 93-108.

[18] MORITA, Y., UMEDA, T. and KIMURA, Y. Effects of Zr content on phase transformation and magnetic properties of $\mathrm{Sm}(\mathrm{Co}, \mathrm{Cu}, \mathrm{Fe}, \mathrm{Zr}$ )7-9 magnet alloys. Journal of the Japan Institute of Metals and Materials. 1988. vol. 52, no. 2, pp. 243-250.

[19] BURKHANOV, G. S., DORMIDONTOV, N. A., KOLCHUGINA, N. B. and DORMIDONTOV, A. G. Effect of sintering in a hydrogen atmosphere on the density and coercivity of $(\mathrm{Sm}, \mathrm{Zr})(\mathrm{Co}, \mathrm{Cu}, \mathrm{Fe}) \mathrm{Z}$ permanent magnets. In IOP Conf. Series: Materials Science and Engineering. 2018. vol. 347, 012023. 